\title{
Aplikasi Sistem Pakar Untuk Mendeteksi Kerusakan Pada Mobil di Bengkel Citra Motor dengan Menggunakan Visual Basic 6.0
}

\author{
Susanto Haryanto \\ Program Studi Sarjana Teknologi Informatika \\ Fakultas Science and Technic \\ Universitas Buddhi Dharma \\ Jl. Imam Bonjol No. 41, Tangerang Banten Indonesia \\ david_wijaya90@yahoo.co.id
}

\begin{abstract}
Abstrak- Berkembangnya teknologi dizaman ini serta pengembangan dalam pendeteksian suatu kerusakan pada mobil dari sebuah gejala-gejala yang timbul merupakan penyebab dari kerusakan mobil yaitu dengan adanya aplikasi sistem pakar, dimana dalam aplikasi ini menjelaskan dari beberapa macammacam kerusakan, mulai dari ciri-ciri gejala kerusakan, jenisjenis kerusakan dan solusi dari kerusakan yang terjadi pada mobil. Kebanyakan pemilik mobil masih belum begitu mengerti dari kerusakan-kerusakan yang sering terjadi pada komponen mobil mereka. Dengan sistem ini, penulis mencoba untuk merancang suatu sistem pakar yang dapat membantu pemilik mobil dalam mengatasi permasalahan yang sering timbul pada kerusakan mobil agar pemilik mobil dapat mengetahui apa saja yang perlu diperbaiki, melakukan pengecekan pada saat keadaan darurat, dan yang sering bermasalah pada mobil. Dalam merancang program ini dapat menjelaskan bahwa suatu sistem yang berjalan dengan adanya rancangan algoritma dan basis pengetahuan diantaranya tabel pakar, rule-rule pakar serta dengan pohon keputusan yang mengambarkan suatu program sehingga dengan ini maka program dapat diketahui apa saja yang menjadi kekurangan dan spesifikasi yang dibutuhkan dalam sistem ini. Untuk melengkapi dalam pengujian sistem ini, maka adanya pengumpulan data dengan menggunakan kuisioner untuk mengetahui tingkat kelayakan dan kematangan dari sistem ini sesuai dengan apa yang diharapkan, kemudian dilanjutkan dengan menganalisis proses-proses tersebut. Dengan dirancangnya aplikasi ini, berdasarkan hasil analisa dan pembahasan sistem pada perancangan sistem pakar untuk mendeteksi kerusakan pada mobil yang dilakukan, maka dengan ini dapat menarik beberapa kesimpulan dan saran untuk pengembangan suatu aplikasi sistem pakar ini.
\end{abstract}

Keywords- Pengetahuan, Aplikasi, Sistem pakar, Perancangan sistem, Mobil, Toyota Avanza.

\section{Pendahuluan}

Pada jaman yang sudah maju saat ini, alat transportasi telah menjadi kebutuhan utama. Hal ini terjadi karena alat transportasi telah menjadi kebutuhan sehari-hari bagi manusia untuk melakukan aktivitas sehari-hari dengan melakukan perjalanan atau pun mengunjungi tempat. Dengan adanya alat transportasi seseorang dapat mengunjungi tempat-tempat yang di inginkan baik jauh maupun dekat.

Alat transportasi memiliki berbagai kriteria, mulai dari kendaraan roda dua, roda tiga, roda empat, hingga yang memiliki roda lebih banyak lagi. Dahulu, Kendaraan roda empat hanya dapat di miliki oleh orang yang berpenghasilan tinggi, seperti pemilik perusahaan, jabatan yang tinggi, pengusaha sukses, dan seterusnya. Tetapi seiring jalannya waktu, mitos tersebut sudah tidak berlaku lagi.

Beberapa dari pengguna kendaraan hanya bisa mengendarainya saja tanpa mengerti komponen atau bagian dari kendaraan mereka sehingga terjadi masalah pada kendaraan tersebut, pengguna langsung membawa kendaraan mereka ke bengkel atau tempat reparasi kendaraan tanpa mengetahui penyebab kerusakan apa yang terjadi pada kendaraan mereka.

Hal tersebut dapat merugikan pengguna kendaraan dalam bentuk menghabiskan waktu, tenaga, dan biaya yang harus membawa kendaraan mereka ke bengkel walaupun hanya masalah ringan yang sebenarnya bisa di perbaiki sendiri.

Berdasarkan permasalahan tersebut, maka dibuatlah suatu aplikasi sistem pakar untuk mendeteksi kerusakan pada mobil. Diharapkan dengan adanya sistem pakar ini, dapat membantu para pengguna untuk mengenal komponen yang terdapat pada kendaraannya serta dapat mengatasi dan memberikan solusi apabila terdapat kendaraan yang bermasalah atau rusak.

Adapun tujuan dari penulisan penelitian ini adalah mempermudah mendeteksi kerusakan yang terjadi pada mobil manual, membantu pengguna mobil dalam mengatasi dan mengambil tindakan untuk mengatasi masalah yang timbul pada mobil serta dapat menambah pengetahuan bagi pengguna mobil itu sendiri, dan memberikan solusi dari kerusakan yang terjadi.

Dalam rangka pengumpulan data yang akan dianalisis dalam penelitian ini maka penulis menggunakan metode pengumpulan data berupa Observasi, Wawancara, dan Studi Pustaka. 


\section{Perancangan Sistem}

A. Pembahasan Sistem Berjalan

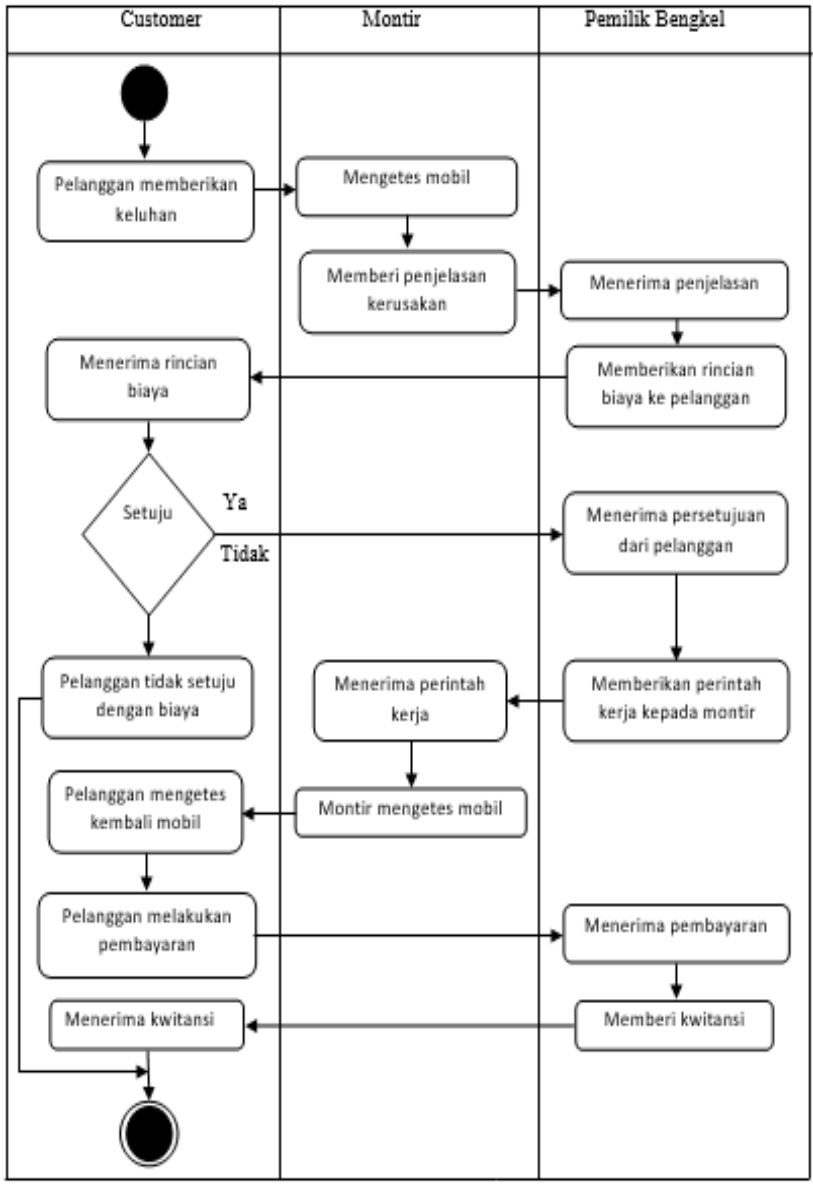

Gambar 2.1 Activity diagram sistem berjalan

\section{1) Permasalahan}

Permasalahan yang timbul pada Bengkel Citra Motor dalam mendeteksi kerusakan pada mobil adalah sebagai berikut:

- Sering kali montir lupa penyebab kerusakan pada mobil sehingga terkadang sulit untuk menetukan apa yang menjadi penyebab kerusakan.

- Pemilik mobil terkadang tidak tahu sama sekali cara mengatasi penyebab kerusakan mobil mereka sehingga pada saat darurat pemilik mobil harus menghubungi call center yang sudah ada.

2) Alternatif pemecahan masalah

Solusi yang akan penulis coba kemukakan ialah :

- Meningkatkan pelayanan terhadap pelanggan.

- Mempercepat proses penentuan permasalahan yang ada pada mobil.

- Membuat suatu interaksi yang positif antara pemilik, montir dengan pelanggan.
- Pembuatan aplikasi sistem pakar untuk mendeteksi kerusakan pada mobil.

\section{B. Perancangan User Interface}
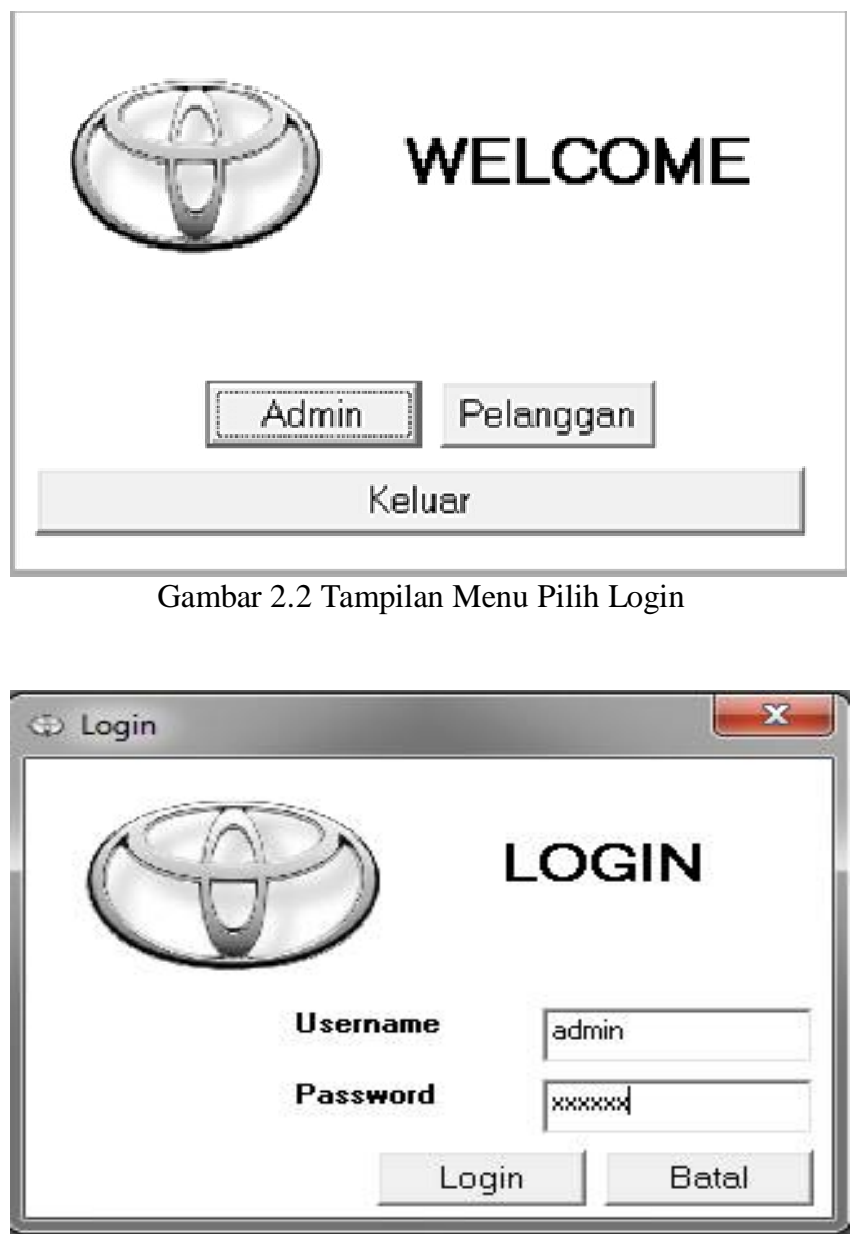

Gambar 2.3 Tampilan Menu Login

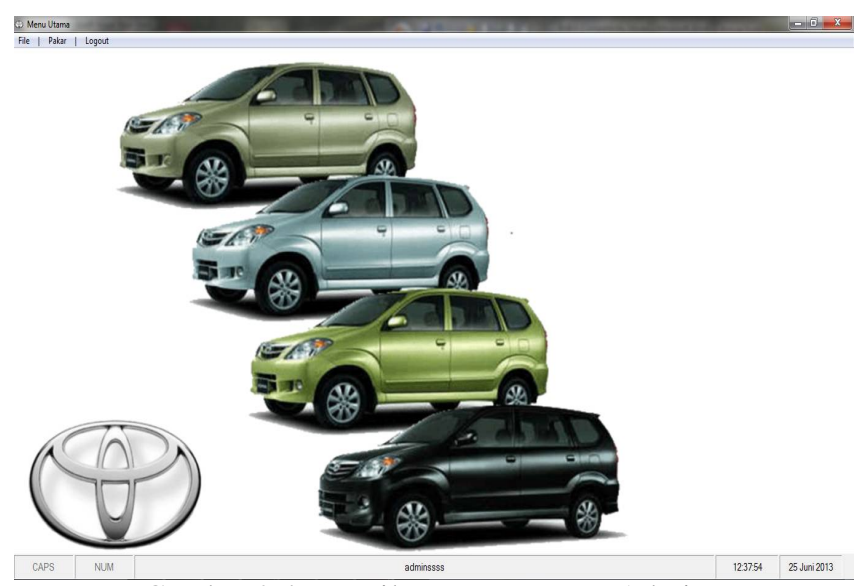

Gambar 2.4 Tampilan Menu Utama Admin 


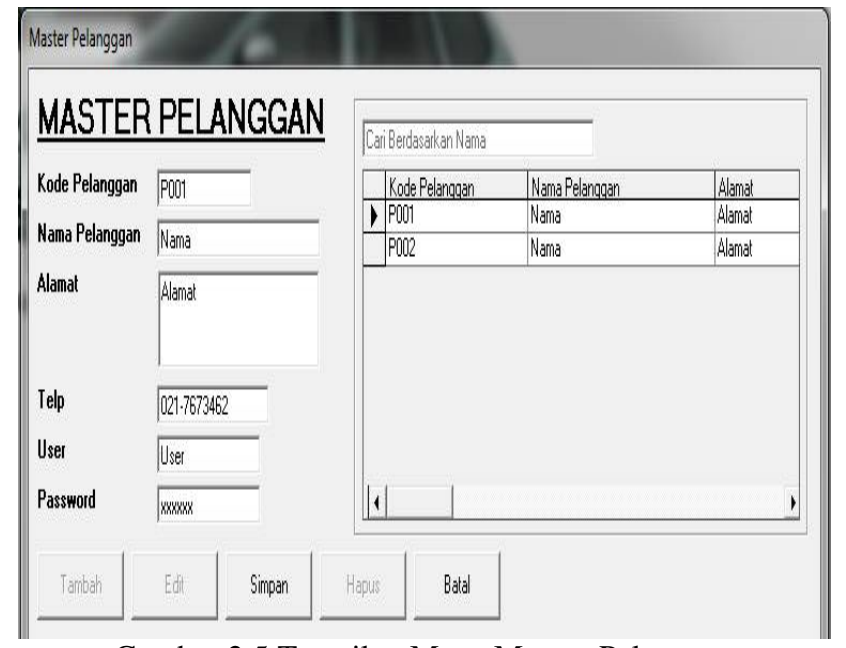

Gambar 2.5 Tampilan Menu Macam Pelanggan

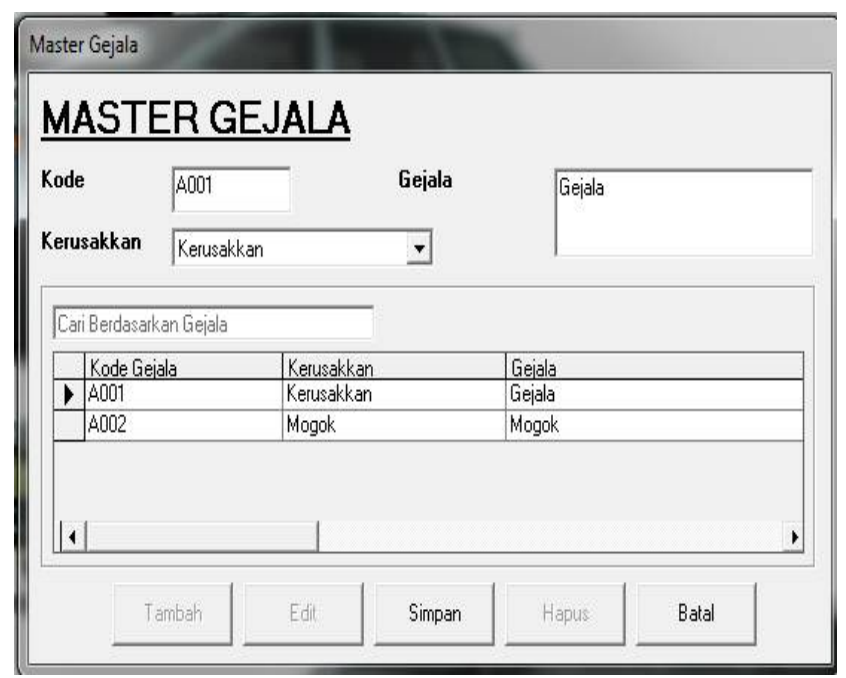

Gambar 2.6 Tampilan Menu Master Gejala

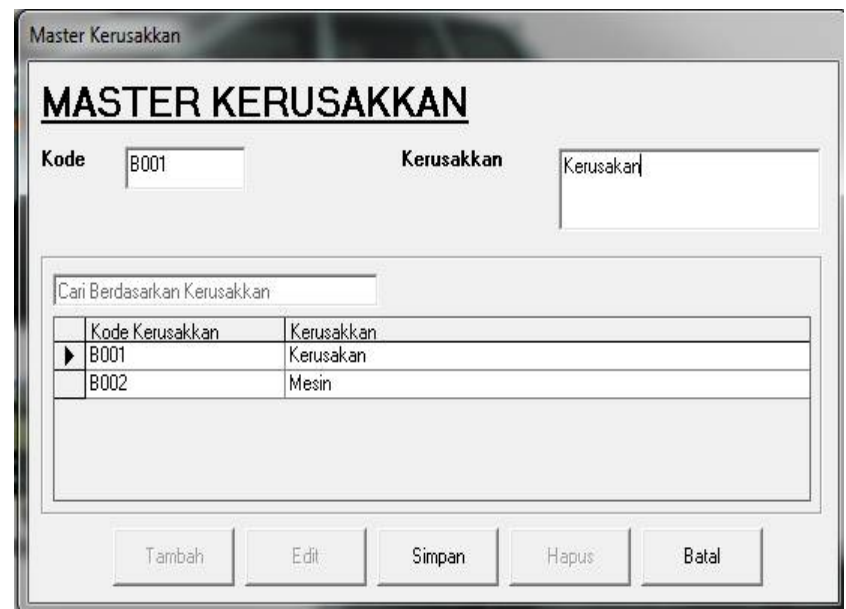

Gambar 2.7 Tampilan Menu Master Kerusakan

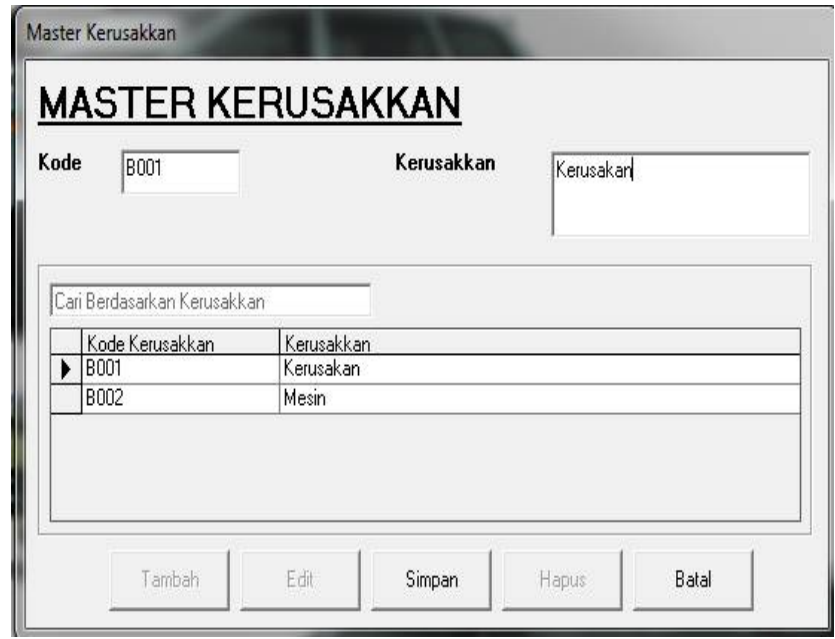

Gambar 2.8 Tampilan Menu Master Solusi

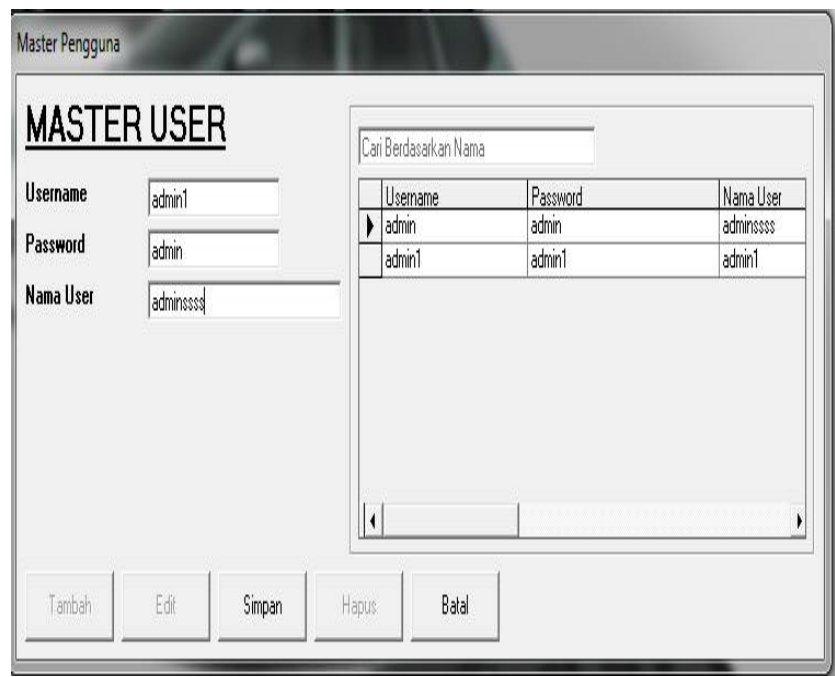

Gambar 2.9 Tampilan Menu Master Pengguna/User

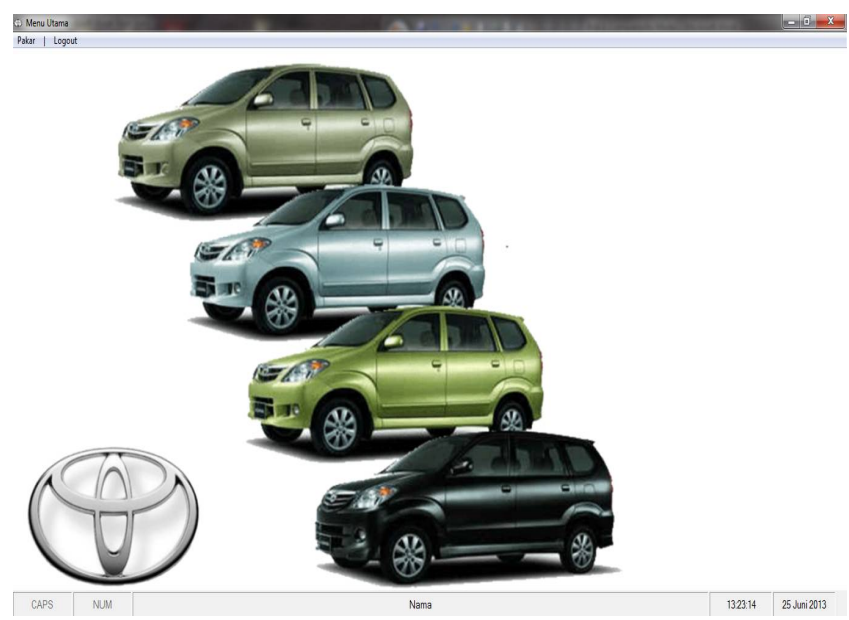

Gambar 2.10 Tampilan Menu Utama Pelanggan 
Jurnal SISFOKOM, Volume 03, Nomor 02, September 2014

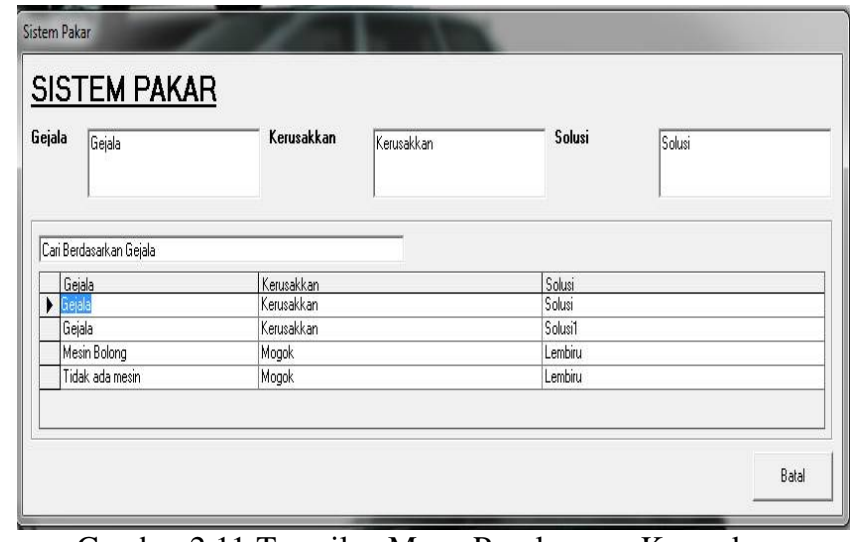

Gambar 2.11 Tampilan Menu Penelusuran Kerusakan

\section{Hasil Pengolahan Kuisioner}

Setelah aplikasi ini selesai, dan akan mengujinya kepada user. Pada tahap ini aplikasi sistem pakar kerusakan mobil diujikan kepada pakar dan pemilik mobil khususnya pemilik mobil yang masih awam atau belum mengerti komponen dari gejala-gejala kerusakan pada mobil mereka. Evaluasi terhadap aplikasi ini dilakukan dengan cara menyebar kuisioner kepada 20 responden. Kemudian responden memberikan tanggapan dan sarannya melalui kuisioner.

Tabel 3.1 Kuisioner

\begin{tabular}{|c|c|c|c|}
\hline \multirow{2}{*}{ No } & \multirow{2}{*}{ Pertanyaan } & \multicolumn{2}{|c|}{ Jawaban } \\
\cline { 3 - 4 } & Ya & Tidak \\
\hline 1 & $\begin{array}{l}\text { Apakah anda suka memperbaiki } \\
\text { mobil ? }\end{array}$ & 5 & 20 \\
\hline 2 & $\begin{array}{c}\text { Apakah anda pernah mengalami } \\
\text { kerusakan pada mobil ? }\end{array}$ & 25 & 0 \\
\hline 3 & $\begin{array}{c}\text { Apakah tampilan antar muka pada } \\
\text { aplikasi sistem pakar untuk } \\
\text { mendeteksi kerusakan pada mobil } \\
\text { menarik? }\end{array}$ & 23 & 2 \\
\hline 5 & $\begin{array}{c}\text { Apakah anda menyukai aplikasi } \\
\text { sistem pakar untuk mendeteksi } \\
\text { kerusakan pada mobil pada tahap uji } \\
\text { coba yang telah dibuat? }\end{array}$ & 25 & 0 \\
\hline 5 & $\begin{array}{c}\text { Apakah aplikasi sistem pakar untuk } \\
\text { mendeteksi kerusakan pada mobil ini } \\
\text { dapat menyelesaikan masalah yang } \\
\text { sering anda alami? }\end{array}$ & 25 & 0 \\
\hline 6 & $\begin{array}{c}\text { Apakah aplikasi sistem pakar untuk } \\
\text { mendeteksi kerusakan pada mobil } \\
\text { merupakan aplikasi pembantu dalam } \\
\text { masalah kerusakan pada mobil ? }\end{array}$ & 25 & 0 \\
\hline 7 & $\begin{array}{c}\text { Apakah aplikasi sistem pakar untuk } \\
\text { mendeteksi kerusakan pada mobil ini } \\
\text { sangat bermanfaat? }\end{array}$ & 25 & 0 \\
\hline 8 & $\begin{array}{c}\text { Apakah aplikasi sistem pakar untuk } \\
\text { mendeteksi kerusakan pada mobil }\end{array}$ & 24 & 1 \\
\hline
\end{tabular}

\begin{tabular}{|c|c|c|c|}
\hline \multirow{2}{*}{ No } & Pertanyaan & \multicolumn{2}{|c|}{ Jawaban } \\
\cline { 3 - 4 } & Ya & Tidak \\
\hline & mudah untuk digunakan? & & \\
\hline 9 & $\begin{array}{c}\text { Menurut anda, apakah aplikasi ini } \\
\text { perlu ditambahkan animasi yang } \\
\text { lebih menarik? }\end{array}$ & 11 & 14 \\
\hline \multirow{2}{*}{10} & $\begin{array}{c}\text { Menurut anda, Apakah pada aplikasi } \\
\text { sistem pakar untuk mendeteksi } \\
\text { kerusakan pada mobil yang telah } \\
\text { dibuat perlu dikembangkan lebih } \\
\text { lanjut? }\end{array}$ & 14 & 11 \\
\hline
\end{tabular}

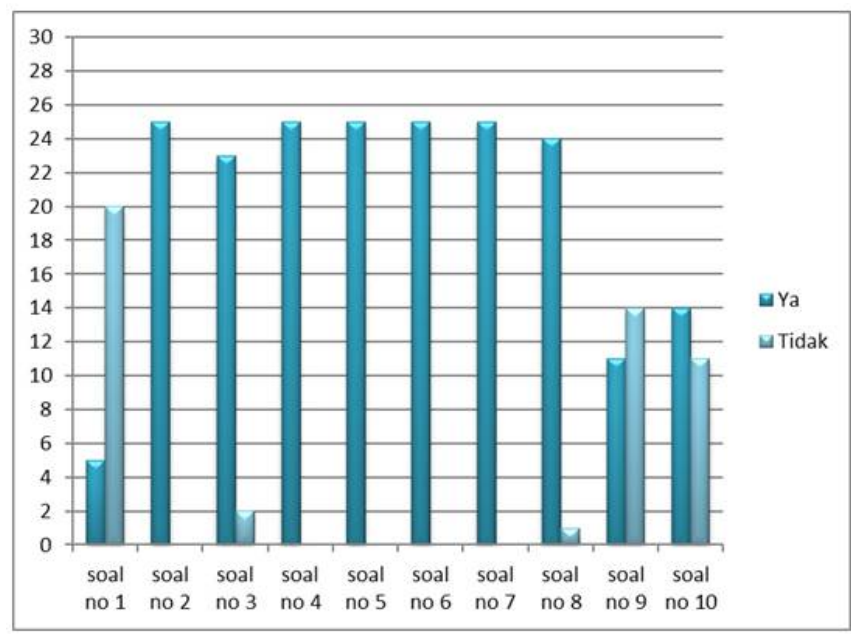

Gambar 3.1 hasil pengolahan data secara keseluruhan

\section{Penutur}

\section{A. Kesimpulan}

Setelah melakukan analisis, perancangan, dan pengujian, maka dapat diperoleh beberapa kesimpulan, antara lain berikut:

- Aplikasi sistem pakar ini dapat melakukan penelusuran kerusakan pada mobil manual.

- Dengan adanya aplikasi ini dapat membantu montir dan pemilik mobil dalam mengatasi kerusakan yang di alami.

- Aplikasi sistem pakar kerusakan pada mobil ini dapat membantu bagi montir pemula dan juga pemilik mobil dalam memperoleh informasi mengenai gejala dan kerusakan yang sering terjadi pada mobil manual serta solusi-solusi untuk menanganinya.

- Dari hasil pengujian dan evaluasi dengan menggunakan kuisioner, dapat di simpulkan bahwa $80 \%$ koresponden menyatakan aplikasi sistem pakar ini dapat membantu bagi para pemilik mobil serta para montir pemula. 


\section{B. Saran}

Di dalam penerapan sistem pakar kerusakan pada mobil yang di usulkan, agar penerapan aplikasi tersebut dapat berjalan dengan baik kedepannya, maka di sarankan:

- Memperbaiki dan memperindah tampilan antarmuka untuk menyajikan kenyamanan penggunaan oleh user.

- Menyajikan solusi kerusakan pada mobil yang lebih detail dengan langkah-langkah penanganan yang rinci dan disertai dengan gambar.

- Meningkatkan dan memperbanyak aspek security untuk melindungi aplikasi dari kemungkinan manipulasi atau pencurian data oleh orang yang tidak bertanggungjawab.

\section{DAFTAR PUSTAKA}

[1] Daryanto, Drs, 2008, Pengetahuan Komponen Mobil, Jakarta: PT Bumi Aksara.
[2] Daryanto, Drs, 2006, Teknik Merawat Automobil Lengkap, Bandung: CV Yrama Widya.

[3] Gondodiyoto, Sanyoto, 2007, Audit Sistem Informasi + Pendekatan, Jakarta: Mitra Wacana Media.

[4] Harto, Widodo Budi, 2005, Panduan Lengkap Pemograman J2EE, Yogyakarta: Andi.

[5] Jogianto, H.M, 2005, Analisis dan Desain Sistem Informasi, Edisi kedua, Yogyakarta: Andi.

[6] Kusrini, 2006, Sistem Pakar, Teori dan Aplikasi, Edisi Pertama, Yogyakarta: Andi Offset.

[7] McLeon, Raymond Jr, 2007, Sistem Informasi Manajemen, Edisi ke-9, Jakarta: PT Indeks.

[8] Northop, RS, 2008, Service Auto Mobil Pengantar Praktis Teknik Otomotif, Bandung: CV Pustaka Setia.

[9] PT. Toyota Astra Motor, 2012, Pedoman Pemilik, Jakarta.

[10] Rumawan,Uus, 2007, Konsep dan Implementasi Visual Basic, Jakarta: PT.Elex Media Komputindo.

[11] Santoso, Harip, 2006, Membuat Multi AplikasiMenggunakan Visual Basic 6.0.

[12] Supriyanto, Ali, 2005, Pengantar Teknologi Informasi, Semarang: Penerbit Salemba Infotek.

[13] T. Sutojo, Edy Mulyanto dan Dr. Vincent Suhartono, 2011, Kecerdasan Buatan, Yogyakarta: Andi. 